\title{
FORMULATION, OPTIMIZATION, AND EVALUATION OF SITAGLIPTIN AND SIMVASTATIN RAPIDLY DISSOLVING TABLETS
}

\author{
ASMAA A. BAYOUMI \\ Pharmacy Department, Ibn Hayyan University College, Karbala, Iraq \\ Email: asmaa.bayoumi79@gmail.com
}

Received: 26 Jun 2018, Revised and Accepted: 14 Aug 2018

\begin{abstract}
Objective: The scope of this work was to formulate sitagliptin and simvastatin rapidly dissolving tablets. However, simvastatin is practically insoluble in water. For improving its poor oral bioavailability and with the aim of facilitating administration to patients facing problems with swallowing rapidly dissolving tablets were prepared
\end{abstract}

Methods: Tablets were prepared using superdisintegrant addition technique using croscarmellose sodium (Ac-di-sol), sodium starch glycolate (explotab) and crospovidone in different percentages. Evaluation tests such as weight variation, thickness, and content variation, and friability, disintegration, wetting time, in vitro dispersion and in vitro dissolution were carried out.

Results: The results showed that the presence of crospovidone could enhance the dissolution rate of simvastatin greatly. The best-optimized formulae found were that F8, F9, and F10 which showed good disintegration and the dissolution rate of simvastatin and sitagliptin was more than $90 \%$ after 10 min while the dissolution rate for simvastatin and sitagliptin pure standards was $12 \%$ and $30 \%$, respectively after 10 min.

Conclusion: Some tablet formulae showed acceptable pharmacotechnical properties and complied with compendium requirements. Results of dissolution studies revealed that F8-F10 showed an increase in the dissolved sitagliptin and simvastatin to be more than $90 \%$ after 10 min.

Keywords: Simvastatin, Sitagliptin, Rapidly dissolving tablets, Superdisintegrants, Crospovidone

(c) 2018 The Authors. Published by Innovare Academic Sciences Pvt Ltd. This is an open access article under the CC BY license (http://creativecommons.org/licenses/by/4.0/) DOI: http://dx.doi.org/10.22159/ijap.2018v10i5.28122

\section{INTRODUCTION}

Many patients with type 2 diabetes are affected by hypercholesterolemia. Therefore, the combination of antidiabetic and anti-hypercholesterolemia is appreciated as Juvisync $®$ convenient tablets which are a combination of sitagliptin and simvastatin. In this work, sitagliptin and simvastatin rapidly dissolving tablets were formulated to achieve faster release than the convenient tablets and more suitable for elderly patients who face difficulty in swallowing. The literature lacks trials of the formulation of simvastatin and sitagliptin combination in rapidly dissolving tablets dosage form.

There are different technologies used for manufacturing fastdissolving tablets, such as freeze-drying, spray-drying, tablet molding, sublimation, sugar-based excipients, tablet compression, and disintegration addition $[1,2]$. In this work, simvastatin, and sitagliptin rapidly dissolving tablets were prepared using the easiest technique which is superdisintegrant addition.

Sitagliptin phosphate monohydrate is described chemically as 7-[(3R)3-amino-1-oxo-4-(2,4,5-trifluorophenyl)butyl]-5,6,7,8-tetra-hydro-3(trifluoromethyl)-1,2,4-triazolo[4,3-a] pyrazine phosphate (1:1) monohydrate, with the structural formula shown in fig. 1. Simvastatin is butanoic acid, 2,2-dimethyl-,1,2,3,7,8,8a-hexahydro-3,7-dimethyl-8-[2(tetrahydro-4-hydroxy-6-oxo-2H-pyran-2-yl)-ethyl]-1-naphthalenyl ester, $\left[1 S-\left[1 \alpha, 3 \alpha, 7 \beta, 8 \beta\left(2 S^{*}, 4 S^{*}\right),-8 a \beta\right]\right]$, with the structural formula [3] shown in fig. 2.

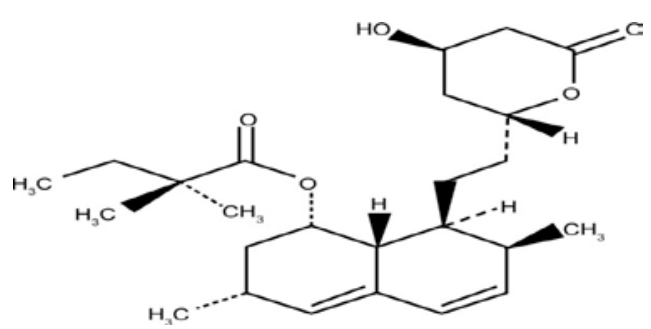

Fig. 1: Chemical structure of simvastatin

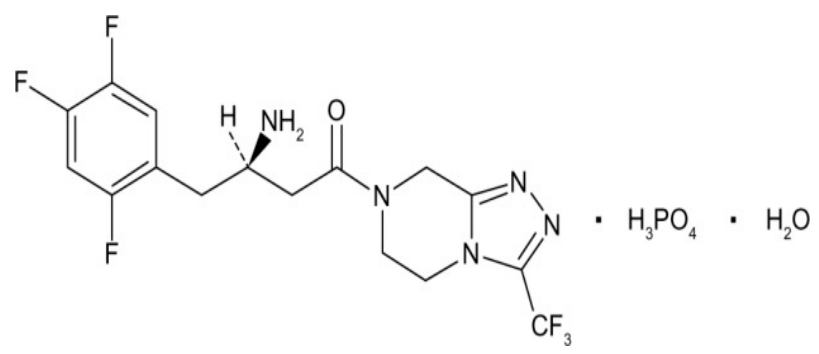

Fig. 2: Chemical structure of sitagliptin phosphate monohydrate

\section{MATERIALS AND METHODS}

\section{Materials}

Simvastatin and sitagliptin phosphate monohydrate purchased from Virdev, India. Explotab, microcrystalline cellulose (avicel PH 101), croscarmellose sodium (ac-di-sol), lactose monohydrate, magnesium stearate and crospovidone; kindly supplied by; Memphis pharmaceutical chemicals company, Cairo, Egypt. Acetonitrile for HPLC; Merck, Darmstadt, Germany. Hydrochloric acid, phosphoric acid, potassium dihydrogen phosphate; El-Nasr pharmaceutical chemicals company, Cairo, Egypt. High purity water was prepared by using a Waters Milli-Q plus purification system.

\section{Methodology}

\section{Development of HPLC assays}

Two methods were developed to determine drug content of simvastatin and sitagliptin, dissolution rate in combination.

\section{Preparation of standard solution}

$40 \mathrm{mg}$ simvastatin and $100 \mathrm{mg}$ sitagliptin were weighed accurately, transferred into a $100 \mathrm{ml}$ measuring flask, $50 \mathrm{ml}$ methanol was added, shaken to dissolve by sonication for $5 \mathrm{~min}$, completed the volume with methanol and mixed well. 


\section{Preparation of test solution}

Ten tablets were weighed, and the average weight of one tablet was found out and ground. A weight of powdered tablet equivalent to the weight of one tablet was transferred into a $100 \mathrm{ml}$ volumetric flask, about $50 \mathrm{ml}$ methanol was added, sonicated for $15 \mathrm{~min}$, completed the volume using methanol, mixed well and filtered through $0.45 \mu \mathrm{m}$ membrane filter.

\section{Chromatographic conditions}

The separation was achieved using a Kromasil $₫$, USA C18 (5 $\mu \mathrm{m}, 25$ $\mathrm{cm} \times 4.6 \mathrm{~mm}$ ) column, Waters HPLC apparatus consisting of pump 1525 and a UV/VIS detector 2487. The injection volume was $100 \mu \mathrm{l}$ and a mobile phase consisting of acetonitrile: water $65: 35$ and adjust $\mathrm{pH}$ to 4 with phosphoric acid while at a flow-rate of $0.8 \mathrm{ml} / \mathrm{min}$ in case of simvastatin and $1.2 \mathrm{ml} / \mathrm{min}$ in case of sitagliptin which was detected at $266 \mathrm{~nm}$ while simvastatin was detected at $235 \mathrm{~nm}$.
Linearity ranges were $10-70 \mu \mathrm{g} / \mathrm{ml}$ and $5-30 \mu \mathrm{g} / \mathrm{ml}$ for sitagliptin and simvastatin, respectively.

\section{Tablets preparation}

Simvastatin and $50 \%$ of diluents were mixed and sieved using sieve No. 30 then kneaded with butylated hydroxyanisole dissolved in the least amount of alcohol. Then dried in an air oven till no odor of ethanol, then at a temperature not exceeding $50^{\circ} \mathrm{C}$ and sieved using sieve No. 30. The dried, sieved granules were mixed geometrically with the rest of diluent, disintegrant and sieved using sieve No. 30 and finally mixed with sieved lubricant (magnesium stearate).

Tablets were compressed on flat punch $10 \mathrm{~mm}$. All tablets were compressed into 330-mg using a single punch tablet machine [Erweka, Germany]. The force of compression was kept constant throughout the compression process shown in table 1.

Table 1: Formulae of the rapidly dissolving simvastatin and sitagliptin tablets

\begin{tabular}{|c|c|c|c|c|c|}
\hline \multirow[t]{2}{*}{ Formula } & \multicolumn{2}{|l|}{ Diluent } & \multicolumn{3}{|l|}{ Disintegrant } \\
\hline & Avicel PH 101 (mg) & Mannitol (mg) & Explotab (mg) & Ac-di-sol (mg) & Crospovidone \\
\hline F 1 & 123.1 & ------ & 30 & ------- & -------- \\
\hline F 2 & 123.1 & ------ & ----- & 30 & ------- \\
\hline F 3 & 123.1 & ------ & ------- & ------- & 30 \\
\hline F 4 & -------- & 123.1 & 30 & -------- & ----- \\
\hline F 5 & ------ & 123.1 & ------- & 30 & -------- \\
\hline F 6 & -------- & 123.1 & -------- & ------ & 30 \\
\hline F7 & 45 & 48.1 & ------- & ------- & 60 \\
\hline F 8 & 28 & 35.1 & -------- & -------- & 90 \\
\hline F 9 & 23 & 30.1 & -------- & ------- & 100 \\
\hline $\mathrm{F} 10$ & 13 & 20.1 & -------- & -------- & 120 \\
\hline
\end{tabular}

*each tablet contains $128.5 \mathrm{mg}$ sitagliptin phosphate monohydrate, $40 \mathrm{mg}$ simvastatin, $0.4 \mathrm{mg}$ butylated hydroxyanisole, $2 \mathrm{mg}$ aspartame and $6 \mathrm{mg}$ magnesium stearate

\section{Evaluation of post-compression properties \\ Weight variation}

Twenty tablets, from each formula, were individually weighed [Sartorius, Gottingen, Germany]. The mean weight of the tablets was calculated [4]

\section{Content uniformity}

The uniformity of content was determined by crushing ten tablets from each formula and determining the drug content of each tablet individually using the developed HPLC method [4].

\section{Friability}

Ten tablets of each formula were accurately weighed and placed in the drum of a friablator [Pharma Test, Germany], which rotated at $25 \mathrm{rpm}$ for a period of $4 \mathrm{~min}$. The tablets were then brushed and reweighed. The percentage loss in weights was calculated and taken as a measure of friability [4].

\section{Hardness}

Ten tablets of each formula were tested for their hardness [Tablet Hardness Tester, Erweka, Germany]. The mean hardness in kilograms was then determined [4].

\section{Disintegration time}

The disintegration time for each of six tablets of each formula was determined using the USP disintegration tester [USP Disintegration, Pharma Test, Germany] [4].

\section{In vitro dispersion time test}

Ten ml measuring cylinder was taken in which $6 \mathrm{ml}$ distilled water was added then a tablet was dropped on it. The time for the tablet to completely disintegrate into fine particles was determined. Three tablets from each formulation were tested, and results were expressed in seconds $[5,6]$.

\section{Wetting time}

Five circular tissue papers of $10 \mathrm{~cm}$ diameter were placed in a Petri dish with a $10 \mathrm{~cm}$ diameter. Ten millimeters of water-containing Eosin, a water-soluble dye were added to Petri dish. A tablet was carefully placed on the surface of the tissue paper. The time required for water to reach the uppermost surface of the tablet was determined [6].

\section{Water absorption ratio}

A piece of tissue paper was folded twice and placed in a small Petri dish containing $6 \mathrm{ml}$ of water. A tablet was put on the paper. The wetted tablet was then weighed. Water absorption ratio (R), was calculated by the following equation:

$$
R=10(W a / W b)
$$

Where $\mathrm{Wb}$ is the weight of the tablet before water absorption and Wa is the weight of the tablet after water absorption [7].

\section{In vitro dissolution studies}

The test was performed in $10 \mathrm{~mm}$ sodium phosphate buffer containing $1 \%$ tween 80 with $50 \mu \mathrm{g} / \mathrm{ml}$ butylated hydroxyanisole at a temperature of $37^{\circ} \mathrm{C} \pm 0.5^{\circ} \mathrm{C}$ using the USP dissolution tester [Dissolution Apparatus Validata SR 6, Hanson Research Corporation, USA]. Apparatus II (paddle), at a rotation of $50 \mathrm{rpm}$ [8]. Aliquots, each of $5 \mathrm{ml}$ of the dissolution medium were withdrawn at $5,10,15$, 20, 30 and $45 \mathrm{~min}$ intervals. The samples withdrawn were then filtered, adequately diluted and analyzed for sitagliptin and simvastatin by developed HPLC assays. A similar volume of medium was added to the dissolution medium in order to maintain sink conditions, and a correction factor was included [9].

\section{RESULTS AND DISCUSSION}

Formulations post-compression properties were shown in table 2. All formulations were evaluated for weight variation and results indicated very low weight variation which lies within pharmacopeia limits $\pm 5 \%$, this may be due that all formula were prepared by wet granulation. Hardness was seen to be in the range of values of 4.3 to $6.4 \mathrm{~kg} / \mathrm{cm} 3$. Friability of all formulae was less than $1 \%$ and the disintegration time of formulae tablets F8-F10 was in the range of 31 to $43 \mathrm{~s}$ where crospovidone was in percent of $27-36 \%$ of the tablet weight, which may be because crospovidone has been proved to result in fast volume expansion and hydrostatic pressures allowing tablet disintegration [10]. In vitro dispersion time of formulae tablets, F8-F10 was in the 
range of 40 to $59 \mathrm{sec}$. wetting time was in the range of 48 to $130 \mathrm{sec}$. Water absorption ratio was in the range of $40 \%$ to $149 \%$.

The dissolution rate of simvastatin $\mathrm{Q}_{10}$ from $\mathrm{F} 9, \mathrm{~F} 10$ formulae was more than $90 \%$ and shown in fig. 3 , this may be, because of the increase in the concentration of crospovidone resulted in the particles were exposed to dissolution medium at the comparatively faster rate. Also, the presence of crospovidone in the dissolution medium kept the drug particles in dispersed condition, i.e., aggregation of drug particles was avoided and also increase the wetting of dispersed particles due to fixation of hydrophobic drug particles upon hydrophilic crospovidone during the tabletting process resulting primarily in improvements of dissolution and bioavailability due to enhanced solubility [11].

In comparison with the previous studies of researchers such as Prasanthi S, et el [12] prepared simvastatin and sitagliptin tablets by direct compression using pregelatinized starch and explotab as disintegrant, the optimized formula showed dissolution rate of $71.25 \%$ and $69.56 \%$ for simvastatin and sitagliptin, respectively after 10 min while in my study the dissolution rate was more than $90 \%$ after $10 \mathrm{~min}$ for both simvastatin and sitagliptin in the formulae F7, F8, and F9. This comparison proved that there is a significant improvement in my work regarding the dissolution rate.

Table 2: Physicochemical properties of the prepared tablets

\begin{tabular}{|c|c|c|c|c|c|c|c|c|}
\hline Formula & $\begin{array}{l}\text { Tablet } \\
\text { weight*(mg) }^{*}(\mathrm{mg}\end{array}$ & $\begin{array}{l}\text { Hardness* } \\
\text { (kg/cm3) }\end{array}$ & $\begin{array}{l}\text { Disintegr-tion } \\
\text { time* (s) }\end{array}$ & $\begin{array}{l}\text { Drug } \\
\text { content* } \\
(\%)\end{array}$ & $\begin{array}{l}\text { Wetting } \\
\text { time }^{*}(\mathrm{~S} \pm \mathrm{SD})\end{array}$ & $\begin{array}{l}\text { Water } \\
\text { absorption } \\
\text { ratio* }(\%) \pm S D\end{array}$ & $\begin{array}{l}\text { In vitro } \\
\text { dispersion } \\
\text { time }^{*}(\mathrm{~s})\end{array}$ & Friability $^{*}$ \\
\hline F1 & $329 \pm 0.22$ & $5.3 \pm 0.05$ & $210 \pm 1.19$ & $99.54 \pm 0.82$ & $130 \pm 0.0$ & $40 \pm 0.31$ & $260 \pm 0.55$ & $0.125 \pm 0.12$ \\
\hline $\mathrm{F} 2$ & $330 \pm 0.45$ & $5.6 \pm 0.26$ & $190 \pm 0.95$ & $97.30 \pm 1.01$ & $114 \pm 0.3$ & $47 \pm 0.35$ & $260 \pm 0.32$ & $0.012 \pm 0.31$ \\
\hline F3 & $331 \pm 0.55$ & $5.2 \pm 0.34$ & $164 \pm 1.13$ & $99.39 \pm 1.31$ & $112 \pm 1.2$ & $43 \pm 1.22$ & $245 \pm 0.25$ & $0.097 \pm 0.26$ \\
\hline F4 & $332 \pm 0.19$ & $4.8 \pm 0.09$ & $140 \pm 1.34$ & $98.92 \pm 1.21$ & $101 \pm 1.0$ & $30 \pm 1.2$ & $230 \pm 0.34$ & $0.175 \pm 0.36$ \\
\hline F5 & $330 \pm 0.33$ & $5.3 \pm 0.08$ & $131 \pm 1.19$ & $99.0 \pm 1.08$ & $93 \pm 0.22$ & $35 \pm 0.23$ & $210 \pm 0.79$ & $0.071 \pm 0.19$ \\
\hline F6 & $329 \pm 0.6$ & $5.9 \pm 0.12$ & $110 \pm 1.25$ & $96.96 \pm 1.28$ & \pm 0.1481 & $36 \pm 0.14$ & $112 \pm 0.17$ & $0.157 \pm 0.1$ \\
\hline F7 & $331 \pm 0.29$ & $4.3 \pm 0.15$ & $90 \pm 1.13$ & $98.09 \pm 1.07$ & $74 \pm 0.11$ & $71 \pm 0.51$ & $108 \pm 0.23$ & $0.089 \pm 0.16$ \\
\hline F88 & $329 \pm 0.6$ & $5.1 \pm 0.11$ & $43 \pm 0.93$ & $99.60 \pm 1.33$ & $61 \pm 0.22$ & $84 \pm 0.36$ & $59 \pm 0.42$ & $0.39 \pm 0.12$ \\
\hline F9 & $330 \pm 0.18$ & $6.1 \pm 0.21$ & $32 \pm 0.22$ & $100.14 \pm 0.5$ & $50 \pm 0.14$ & $140 \pm 0.12$ & $46 \pm 0.21$ & $0.084 \pm 0.25$ \\
\hline F10 & $332 \pm 0.18$ & $6.4 \pm 0.11$ & $31 \pm 0.12$ & $98.09 \pm 1.07$ & $48 \pm 0.22$ & $149 \pm 0.12$ & $40 \pm 0.17$ & $0.175 \pm 0.36$ \\
\hline
\end{tabular}

*All values are reported as mean \pm standard deviation (SD), $\mathrm{n}=5$.

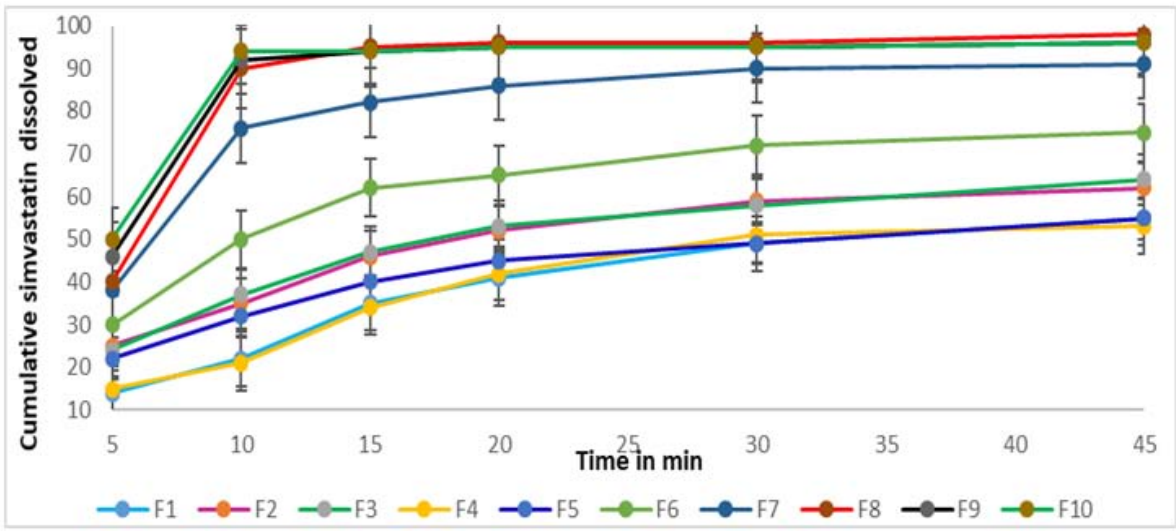

Fig. 3: Dissolution profile of simvastatin from prepared tablets, (All values are reported as mean \pm standard deviation (SD), $n=6$ )

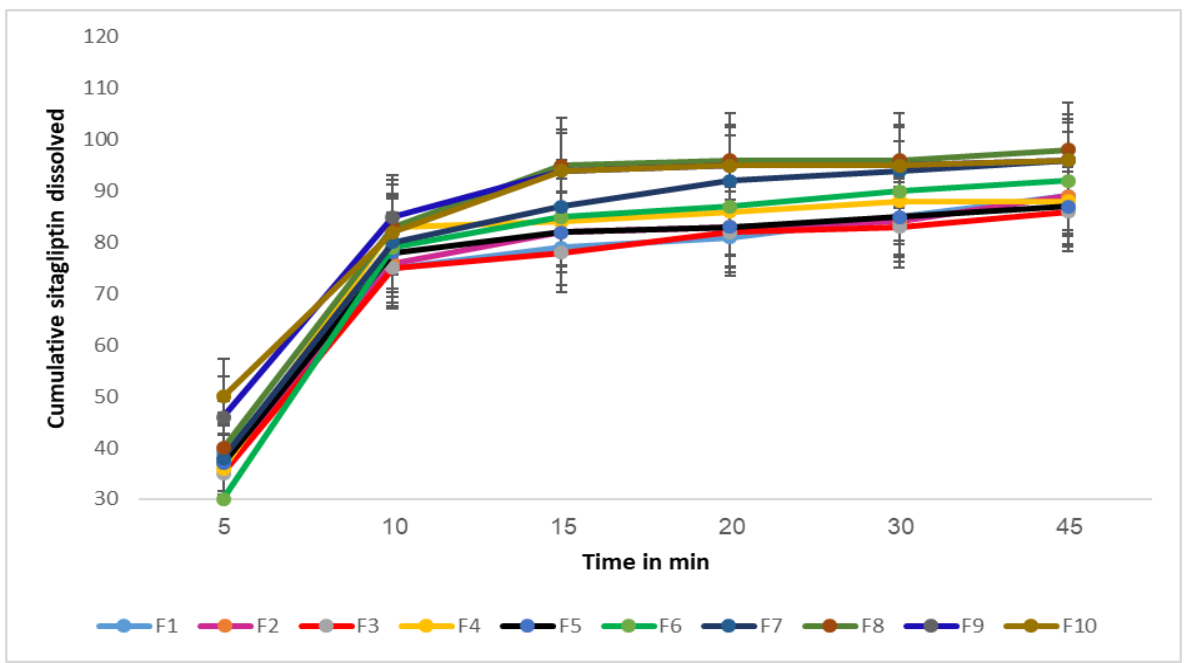

Fig. 4: Dissolution profile of sitagliptin from prepared tablets, (All values are reported as mean \pm standard deviation (SD), $n=6$ ) 


\section{CONCLUSION}

This study showed a new dosage form of simvastatin and sitagliptin which is rapidly dissolving tablets dosage form. Superdisintegrant addition technique using crospovidone could increase the dissolution of simvastatin and sitagliptin to be more than $90 \%$ after 10 min in the formulae F 8, F 9 and F10 prepared with crospovidone in the range of $27-36 \%$, while the dissolution of pure standards of simvastatin and sitagliptin were $12 \%$ and $30 \%$, respectively after 10 min showing a great enhancement in the dissolution and the disintegration time was less than $50 \mathrm{sec}$.

\section{CONFLICT OF INTERESTS}

There is no conflict of interest.

\section{REFERENCES}

1. Chundawat SL, Sharma V. Formulation evaluation, and optimization of orodispersible tablets of pantoprazole sodium by the using of different superdisintegrants. Asian J Pharm Clin Res 2018;11:84-9.

2. Kumar S, Garg KRS. Fast dissolving tablets (Fdts): current status, new market opportunities, recent advances in manufacturing technologies and future prospectsissn. Int J Pharm Pharm Sci 2014;6:22-35.

3. Ramadan WH, Kabbara WK. Sitagliptin/Simvastatin: a first combination tablet to treat type 2 diabetes and hypercholesterolemia-a review of its characteristics. Vasc Health Risk Manag 2015;11:125-32.
4. "The Pharmacopoeia of United States of America". 35 National Formulary 30, Mack Publishing Co. Easton. Vol. 2. Electronic version; 2012.

5. Yunxia B, Hisakazu S, Yorinobu Y, Kazumi D, Akinobu O, Kotaro I. Preparation and evaluation of compressed tablet rapidly disintegrating in the oral cavity. Chem Pharm Bull 1996;44:2121-7.

6. Hari K, Rajeswari S, Ramanamurthy VK. Preparation and evaluation of orally disintegrating tablets of drotaverine hydrochloride using sublimation technique. Int J Pharm Pharm Sci 2018;10:85-95.

7. Ashish P, Mishra P, Main P, Harsoliya M, Agrawal S. A review on recent advancement in the development of the rapid disintegrating tablet. Int J Life Sci Pharm Res 2011;1:7-16.

8. https://www.accessdata.fda.gov/scripts/cder/dissolution/dsp _SearchResults. cfm. [Last accessed on 20 May 2018]

9. Aronson H. Correction factor for dissolution profile calculations. J Pharm Sci 1993;82:1190.

10. Battu SK, Repka MA, Majumdar S, Rao YM. Formulation and evaluation of rapidly disintegrating fenoverine tablets: effect of superdisintegrants. Drug Dev Ind Pharm 2007;33:1225-32.

11. Makiko F, Hideko O, Yu Suke S, Honami T, Masuo K, Yoshiteru $\mathrm{W}$. Preparation, characterization, and tableting of a solid dispersion of indomethacin with crospovidone. Int J Pharm 2005;293:145-53.

12. Prasanthi S, Prasad RA, Kumar GY, Babu NR. formulation and evaluation of sitagliptin phosphate and simvastatin bilayered tablets. Indo Am J Pharm Res 2015;5:3654-66. 